\title{
L-band scintillations and calibrated total electron content gradients over Brazil during the last solar maximum
}

\author{
Claudio Cesaroni ${ }^{1,}{ }^{*}$, Luca Spogli ${ }^{1,6}$, Lucilla Alfonsi ${ }^{1}$, Giorgiana De Franceschi ${ }^{1}$, Luigi Ciraolo ${ }^{2}$, \\ Joao Francisco Galera Monico ${ }^{3}$, Carlo Scotto ${ }^{1}$, Vincenzo Romano ${ }^{1,6}$, Marcio Aquino ${ }^{4}$, and Bruno Bougard ${ }^{5}$ \\ 1 Upper Atmosphere Department, Istituto Nazionale di Geofisica e Vulcanologia, 00143 Rome, Italy \\ *Corresponding author: claudio.cesaroni@ingv.it \\ 2 Atmospheric Physics and Radio Propagation Laboratory, International Centre for Theoretical Physics, 34151 Trieste, Italy \\ 3 Universidad Estadual Paulista, Faculdade de Ciências e Tecnologia, 19060-900 Presidente Prudente, Brazil \\ 4 Nottingham Geospatial Institute, University of Nottingham, NG7 2RD Nottingham, UK \\ 5 Septentrio N.V., 3001 Leuven, Belgium \\ 6 SpacEarth Technology Srl, 00143 Rome, Italy
}

Received 19 June 2015 / Accepted 16 November 2015

\begin{abstract}
This work presents a contribution to the understanding of the ionospheric triggering of L-band scintillation in the region over São Paulo state in Brazil, under high solar activity. In particular, a climatological analysis of Global Navigation Satellite Systems (GNSS) data acquired in 2012 is presented to highlight the relationship between intensity and variability of the total electron content (TEC) gradients and the occurrence of ionospheric scintillation. The analysis is based on the GNSS data acquired by a dense distribution of receivers and exploits the integration of a dedicated TEC calibration technique into the Ground Based Scintillation Climatology (GBSC), previously developed at the Istituto Nazionale di Geofisica e Vulcanologia. Such integration enables representing the local ionospheric features through climatological maps of calibrated TEC and TEC gradients and of amplitude scintillation occurrence. The disentanglement of the contribution to the TEC variations due to zonal and meridional gradients conveys insight into the relation between the scintillation occurrence and the morphology of the TEC variability. The importance of the information provided by the TEC gradients variability and the role of the meridional TEC gradients in driving scintillation are critically described.
\end{abstract}

Key words. Ionosphere (equatorial) - Total electron content - Climatology - Irregularities - Ionization

\section{Introduction}

Global Navigation Satellite Systems (GNSS) provide continuous position, navigation and time information worldwide. Besides the ability to provide position with accuracy from few meters to few centimetres, or even millimetres, depending on the chosen technique, GNSS also allows one to study physical phenomena in different fields of Earth sciences (Shimada et al. 1990; Bevis et al. 1992; Frezzotti et al. 1998; Blewitt et al. 2006; Larson 2009).

GNSS data are of particular interest for ionospheric studies, because Space Weather conditions greatly influence GNSS integrity, accuracy and availability. The ionosphere is the largest contributor to the error budget for GNSS positioning (Klobuchar \& Abdu 1989). Moreover, the inhomogeneity of ionospheric electron distribution can cause sudden, rapid and irregular fluctuations of the amplitude and phase of the received signals, in an effect termed "ionospheric scintillation" (Wernik \& Liu 1974).

Scintillation can cause degradation on GNSS measurements and, in the worst case, can lead to a signal loss of lock to the satellite, affecting the availability of the service and potentially leading to outages that could last from minutes to hours. Amplitude scintillation is traditionally monitored by means of the $S_{4}$ index, which is the standard deviation of the received power normalized by its mean value, whereas phase scintillation is monitored by the $\sigma_{\phi}$ index, which is the standard deviation of the detrended carrier phase. In modern, high sampling frequency $(50 \mathrm{~Hz})$ receivers for scintillation monitoring, the time intervals in which such indices are calculated are of $60 \mathrm{~s}$ for $S_{4}$ and $1,3,10,30$ and $60 \mathrm{~s}$ for $\sigma_{\phi}$.

Given the morphology of the Earth's magnetic field, the geographic regions in which scintillations are more likely to occur are the polar and the equatorial areas, exacerbating in the low latitude regions (Kintner et al. 2007). At low latitudes, the so-called "fountain effect", due to the interplay between $\mathbf{E} \times \mathbf{B}$ drift, gravity and pressure gradients, leads to an enhancement of ionization in the regions close to $\pm 15^{\circ}$ magnetic latitude. Such enhancements are commonly referred to as the northern and southern crest of the Equatorial Ionization Anomaly (EIA), respectively. The Rayleigh-Taylor instability, caused by the formation of the crests, allows the formation of low ionization patches, known as Ionospheric Plasma Bubbles (IPBs), when some forcing from below (e.g. gravity waves) is present. The small-scale irregularities embedded in the IPBs are the main sources for the scintillation phenomena at low latitudes (Wernik \& Liu 1974). Since the 1950s, several studies (Yeh \& Swenson 1959; Koster 1972; Muella et al. 2013) report that equatorial scintillations are mainly night-time events, occur in particular during the post-sunset hours and that the fluctuations of plasma density producing scintillations are located at altitudes from 200 to $400 \mathrm{~km}$ ( $F$ region peak altitude). 
By analysing ionospheric scintillation data over the São Paulo state region (Brazil), this work aims at contributing to the understanding of the relationship between the ionospheric plasma irregularities and scintillation occurrence. To accomplish this task, the study investigates the correlation of the recurrences of the spatial and temporal distributions of the total electron content (TEC) with amplitude scintillation occurrence, as derived by GNSS data from ground-based receivers acquired during the whole year of 2012. GNSS data from the São Paulo State University (UNESP) Real Time Kinematic Network (URTKN) are used to create regional maps of TEC. A crucial aspect of the data treatment is the calibration of the TEC (i.e. the estimation of the different errors affecting the measurements such as inter-frequency biases, multipath, phase ambiguity and cycle slips), derived from GNSS code and phase carrier delays (Ciraolo et al. 2007), as described in Section 2.2. Calibrated TEC measurements are used to obtain the spatial variations of TEC and create maps of calibrated TEC gradients along geographical North-South and East-West directions. Scintillation is investigated by using a network of multi-frequency, multiconstellation, ionospheric monitoring receivers (Septentrio PolaRxS) installed in São Paulo state. Such network has been deployed and operated in the framework of the CIGALA (Concept for Ionospheric Scintillation Mitigation for Professional GNSS in Latin America, http://cigala.galileoic.org/) and CALIBRA (Countering GNSS high Accuracy applications LImitation due to ionospheric disturbance in BRAzil, http:// www.calibra-ionosphere.net/) projects. To evaluate the climatological behaviour of TEC, TEC spatial gradients and amplitude scintillation, data from the URTKN and from the CIGALA/ CALIBRA network are ingested by the Ground Based Scintillation Climatology (GBSC; Spogli et al. 2009), as described in Section 2.3.

Traditionally, the relation between TEC variation and scintillation is investigated by means of the ROT (Rate of TEC) and, in particular, of the ROTI (ROT Index) (Pi et al. 1997). According to its definition, ROTI mixes both spatial and temporal gradients. The aim of this work is to focus only on the role of spatial gradients in driving scintillation, discriminating also the contribution to the TEC variations due to zonal and meridional gradients.

The paper is organized according to four sections: Section 2 presents the data and the analysis methods; the results are given in Section 3; Section 4 provides a summary of the study, discussing the main achievements.

\section{Data and methods}

\subsection{URTKN and CIGALA/CALIBRA networks}

The UNESP Real Time Kinematic Network (URTKN) is the densest GNSS active network in South America and consists of 13 GNSS stations providing real time data. Each station provides $L_{1}, C_{1}, L_{2}, P_{2}$ data every $15 \mathrm{~s}$ by means of multi-constellation (GPS + GLONASS) receivers. All data are publicly available from the IBGE (Instituto Brasileiro de Geografia e Estatistica) FTP server in Receiver INdependent EXchange (RINEX) observational file format. Table 1 presents the 11 stations used to calculate the TEC during 2012. Data from ROSA and UBA1 stations were not available or were too noisy in the considered period. Data from the URTKN have been continuously acquired during 2012, thus no meaningful data gap is present.

Scintillation activity in the region is monitored by a network of PolaRxS receivers, that are multi-frequency, multi-
Table 1. List of the URTKN stations used to compute TEC values. Station location, station code and geographic coordinates are reported.

\begin{tabular}{llcc}
\hline \hline Station code & \multicolumn{1}{c}{ Location } & Lat. $\left({ }^{\circ} \mathrm{N}\right)$ & Lon. $\left({ }^{\circ} \mathrm{E}\right)$ \\
\hline SPAR & Araçatuba & $-21^{\circ} 11^{\prime}$ & $-50^{\circ} 26^{\prime}$ \\
SPCA & Campinas & $-22^{\circ} 48^{\prime}$ & $-47^{\circ} 03^{\prime}$ \\
NEIA & Cananéia & $-25^{\circ} 01^{\prime}$ & $-47^{\circ} 55^{\prime}$ \\
OURI & Ourinhos & $-22^{\circ} 56^{\prime}$ & $-49^{\circ} 53^{\prime}$ \\
PPTE & Presidente Prudente & $-22^{\circ} 07^{\prime}$ & $-51^{\circ} 24^{\prime}$ \\
SJRP & São José do Rio Preto & $-20^{\circ} 47^{\prime}$ & $-49^{\circ} 21^{\prime}$ \\
POLI & São Paulo & $-23^{\circ} 33^{\prime}$ & $-46^{\circ} 43^{\prime}$ \\
PRMA & Maringá & $-23^{\circ} 24^{\prime}$ & $-51^{\circ} 56^{\prime}$ \\
UFPR & Curitiba & $-25^{\circ} 27^{\prime}$ & $-49^{\circ} 14^{\prime}$ \\
MGVA & Varginha/Cemig & $-21^{\circ} 32^{\prime}$ & $-45^{\circ} 26^{\prime}$ \\
MGIN & Inconfidentes & $-22^{\circ} 19^{\prime}$ & $-46^{\circ} 19^{\prime}$ \\
\hline
\end{tabular}

Table 2. List of the CIGALA/CALIBRA network stations used to compute amplitude scintillation values. Station location, station code and geographic coordinates are reported.

\begin{tabular}{llcc}
\hline \hline Name & \multicolumn{1}{c}{ Location } & Lat. $\left({ }^{\circ} \mathrm{N}\right)$ & Lon. $\left({ }^{\circ} \mathrm{E}\right)$ \\
\hline POAL & Porto Alegre & $-30^{\circ} 04^{\prime}$ & $-51^{\circ} 07^{\prime}$ \\
PRU1 & Presidente Prudente & $-22^{\circ} 07^{\prime}$ & $-51^{\circ} 25^{\prime}$ \\
PRU2 & Presidente Prudente & $-22^{\circ} 07^{\prime}$ & $-51^{\circ} 25^{\prime}$ \\
SJCI & São José dos Campos & $-23^{\circ} 13^{\prime}$ & $-45^{\circ} 52^{\prime}$ \\
SJCU & São José dos Campos & $-23^{\circ} 13^{\prime}$ & $-45^{\circ} 52^{\prime}$ \\
\hline
\end{tabular}

constellation receivers, capable to track simultaneously GPS, GLONASS, GALILEO and SBAS frequencies (Sreeja et al. 2012). Sampling at $50 \mathrm{~Hz}$, the receivers give, among others, the following main output parameters:

1. the $\sigma_{\phi}$ phase scintillation index calculated over different time intervals $(1,3,10,30,60 \mathrm{~s})$;

2. the $S_{4}$ amplitude scintillation index calculated over $60 \mathrm{~s}$;

3. the spectral parameters: spectral slope of the phase Power Spectral Density $(p)$ in the $0.1-25 \mathrm{~Hz}$ range and the spectral strength of the phase power spectrum density $(T)$ at $1 \mathrm{~Hz}(60 \mathrm{~s})$;

All these quantities are calculated for all the available signal frequencies transmitted by the satellites and along the slant path connecting the receiver to the satellite.

Details of the stations of the CIGALA/CALIBRA network used in the present analysis are summarized in Table 2.

Figure 1 shows the location of the URTKN stations (red placemarks) and the CIGALA/CALIBRA scintillation monitoring stations (black and white placemarks) used in the present analysis. In the same figure, the red curve identifies the magnetic equator and the purple isolines represent the total intensity of the geomagnetic field $(F)$ calculated by the spherical harmonics expansion up to the 13th order with IGRF-11 coefficients (Finlay et al. 2010).

Figure 2 shows the percentage of data available from each station during the year 2012 .

\subsection{TEC and TEC spatial gradients}

As mentioned in Section 1, the GNSS code and carrier-phase observables are affected by several frequency-independent 


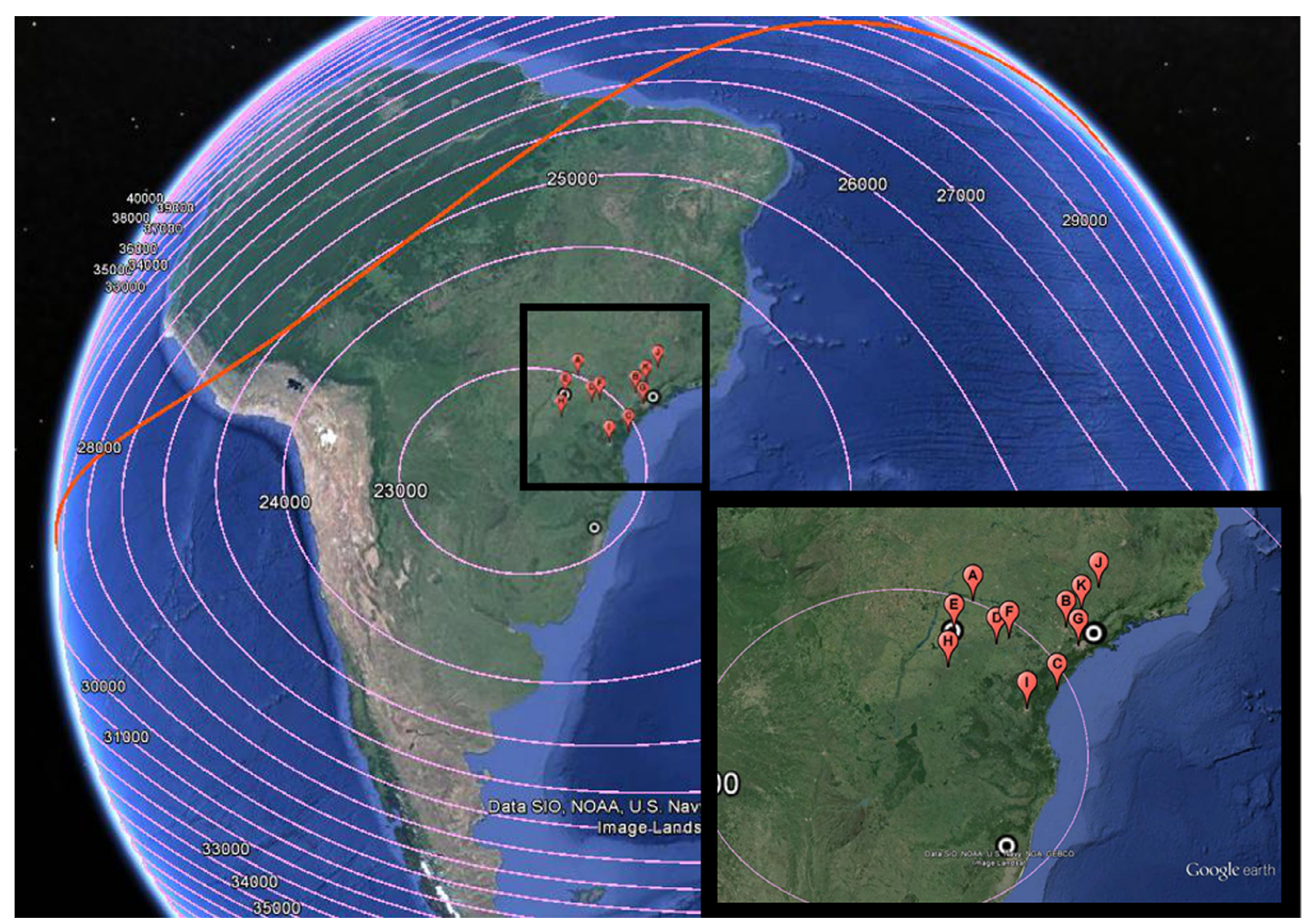

Fig. 1. The URTKN stations (red placemarks) and the CIGALA/CALIBRA scintillation monitoring stations (black and white placemarks) used in the analysis. The red line indicates the magnetic equator and the purple isolines represent the total intensity of geomagnetic field (calculated by IGRF-11 data). White labels report the intensity of the geomagnetic field in nT.

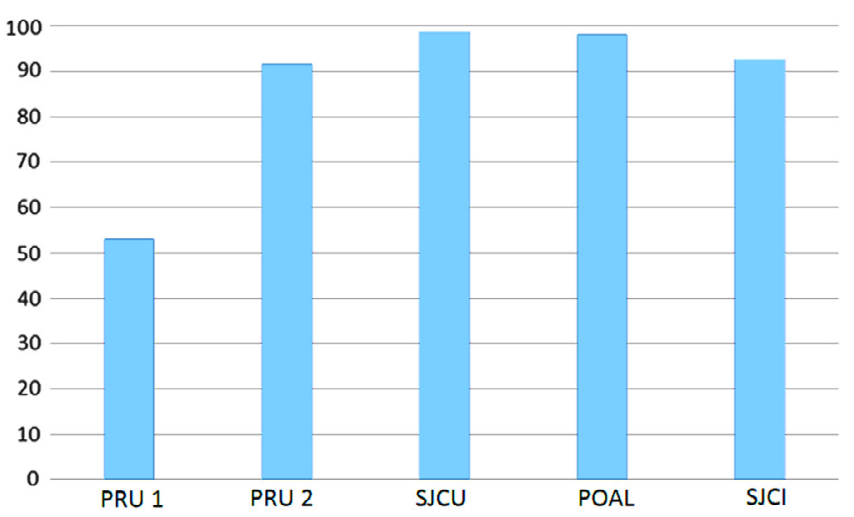

Fig. 2. Data availability in percentage for the CIGALA/CALIBRA network during the year 2012 .

terms and by a dispersive contribution due to the presence of the ionosphere expressed as an excess path:

$$
I=\alpha \frac{\text { STEC }}{f^{2}},
$$

where STEC is the total electron content along the path from the satellite to the receiver in TEC units (TECU) $\left(1 \mathrm{TECU}=10^{16} \mathrm{el} / \mathrm{m}^{2}\right), I$ is the equivalent ionospheric range delay (time delay converted in length unit) at frequency $f$ and $\alpha / f^{2}$ is a conversion factor from TECU to length units. Using simultaneous observations at different frequencies it is possible to obtain an observable that is not affected by frequency-independent errors. Subtracting observations $L_{1}$ and $L_{2}$ (i.e. referred to GPS carriers) in length units the socalled geometry-free linear combination is obtained and a new observable, for both carrier phase and code delay, can be formed for every continuous arc of observation.

Subtracting the two new observables (one for code and one for phase measurements) one can obtain:

$$
\tilde{L}_{\mathrm{arc}}=\mathrm{STEC}+b_{R}+b_{s}+\left\langle\varepsilon_{P}\right\rangle_{\mathrm{arc}},
$$

where $b_{R}$ and $b_{s}$ are the so-called inter-frequency biases (IFB). Equation (2) represents the carrier-phase ionospheric observable "levelled" to the code-delay ionospheric observable. Note that there is no ambiguity term in code-delay observations and the noise and multipath on carrier-phase measurements has been neglected as described in Braasch (1996).

Usually it is assumed that also $\left\langle\varepsilon_{P}\right\rangle_{\text {arc }}$ can be disregarded (Braasch 1996; Mannucci et al. 1998), but considering the co-located stations' experiment described in Ciraolo et al. (2007) it can be noted that this simple assumption does not work in several situations. This empirical evidence suggests maintaining the $\left\langle\varepsilon_{P}\right\rangle_{\text {arc }}$ term in the Eq. (2), trying to estimate bias for each arch instead of single biases for receivers and satellites. Equation (2) becomes

$$
\tilde{L}_{\text {arc }}=\mathrm{STEC}+\beta_{\text {arc }},
$$

that is the basic relation used to calibrate the TEC. 


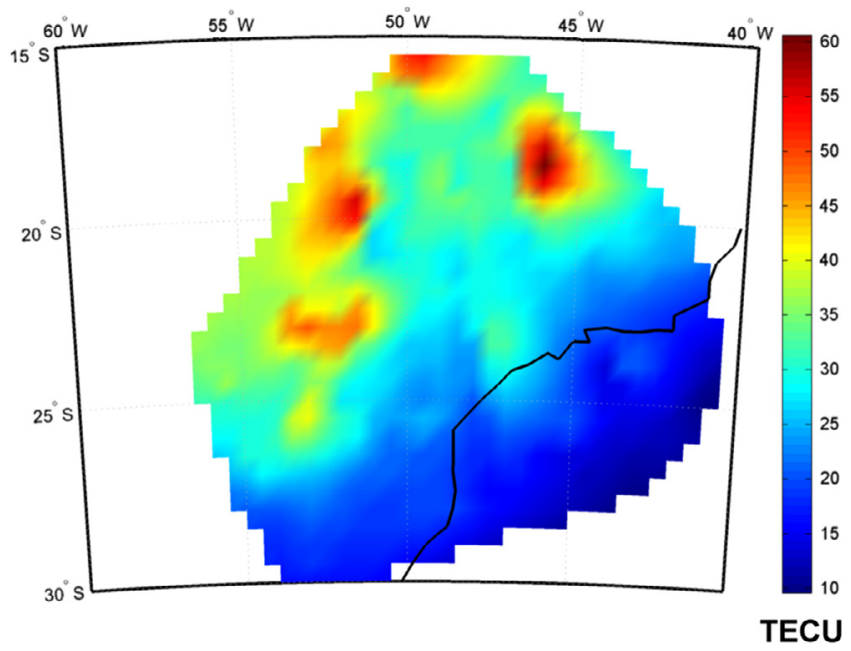

Fig. 3. Example of a map of interpolated TEC as obtained after the calibration procedure applied to $10 \mathrm{~min}$ of URTKN data (12 February from 03:10 to 03:20 UT).

In Eq. (3) $\beta_{\text {arc }}$ is the arc-offset, a constant to be determined for each arc of observations related to a given receiver and satellite pair. $\beta_{\text {arc }}$ represents the contribution of receiver and satellite biases $\left(b_{R}+b_{s}\right)$, and the contribution of any non-zero averaged errors over an arc of observations, e.g. the multipath.

A thin shell (Mannucci et al. 1998) model at $350 \mathrm{~km}$ is used to define the mapping function between the slant and vertical TEC. In order to avoid well-known errors related to the mapping function (Sekido et al. 2003) considering global/ regional solutions, a single station solution is adopted. By interpolating $10 \mathrm{~min}$ of calibrated TEC derived from URTKN measurements, we constructed calibrated TEC maps over the São Paulo state region. The choice of $10 \mathrm{~min}$ is a trade-off between a meaningful statistics to construct each map and the possibility to catch the ionospheric variability on a short time scale. In fact, we assume that within $10 \mathrm{~min}$ the ionosphere is "frozen". Even if this is a strong assumption when applied at low latitudes, some tests carried out during the data analysis showed that an interval of $10 \mathrm{~min}$ is the best compromise between the temporal variability of the ionosphere and a good spatial resolution of the maps.

To realize the TEC maps, the interpolation method known as natural neighbour interpolation technique is adopted. This choice follows what was found by Foster \& Evans (2008), that demonstrated how, in the case of local maps of TEC, the natural neighbour interpolation technique gives better results with respect to other commonly used methods (linear, inverse distance weighting, kriging, etc.). Details on the natural neighbour interpolation technique applied can be found in Okabe et al. (1994) and Lee \& Schachter (1980).

The interpolation is made to obtain the calibrated TEC on a grid of $0.25^{\circ}$ latitude $\times 0.25^{\circ}$ longitude, covering the entire region of São Paulo state. Figure 3 shows an example of such maps, as obtained after the calibration based on $10 \mathrm{~min}$ of URTKN data.

From these TEC maps, we derive maps of TEC gradients along the North-South direction $\left(\Delta \mathrm{TEC}_{\mathrm{N}-\mathrm{S}}\right)$ and East-West direction $\left(\triangle \mathrm{TEC}_{\mathrm{E}-\mathrm{W}}\right)$ by applying the following equations:

$$
\Delta \operatorname{TEC}_{\mathrm{N}-\mathrm{S}}\left(\mathrm{GP}_{i, j}\right)=\frac{\operatorname{TEC}\left(\mathrm{GP}_{i+1, j}\right)-\operatorname{TEC}\left(\mathrm{GP}_{i, j}\right)}{d_{i}},
$$

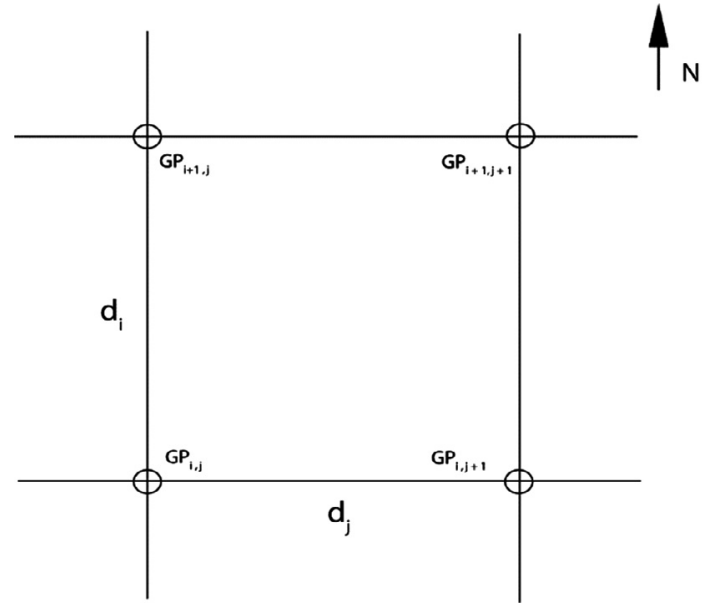

Fig. 4. An example of the grid points useful to explain Eqs. (4) and (5). $d_{i}$ and $d_{j}$ are distances between grid points.

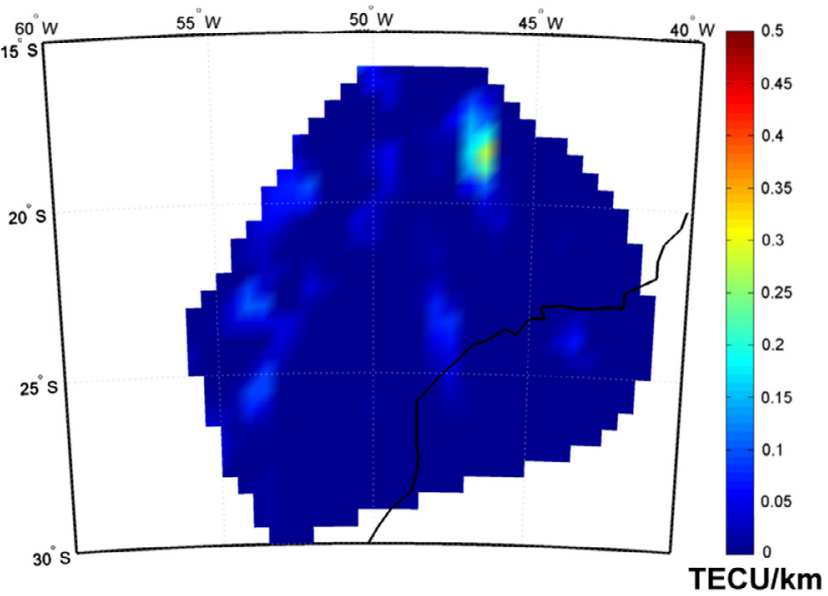

Fig. 5. Example of a map of TEC E-W gradients as obtained from TEC maps in Figure 3.

$$
\Delta \operatorname{TEC}_{\mathrm{E}-\mathrm{w}}\left(\mathrm{GP}_{i, j}\right)=\frac{\operatorname{TEC}\left(\mathrm{GP}_{i, j+1}\right)-\mathrm{TEC}\left(\mathrm{GP}_{i, j}\right)}{d_{j}},
$$

where $\Delta \mathrm{TEC}_{\mathrm{N}-\mathrm{S}}\left(\mathrm{GP}_{i, j}\right)$ is the TEC gradient along the NorthSouth direction calculated for the grid point (GP) with coordinates $(i, j)$, TEC $\left(\mathrm{GP}_{i+1, j}\right)$ is the TEC value of the first northerly point of the grid with respect to $(i, j), \operatorname{TEC}\left(\mathrm{GP}_{i, j}\right)$ is the TEC value of the considered grid point $(i, j)$ and $d_{i}$ is the distance between $(i+1, j)$ and $(i, j)$ points. Analogous terms are used in Eq. (5) in which TEC $\left(\mathrm{GP}_{i, j+1}\right)$ is the easterly point of the grid with respect to $(i, j)$. Symbols used in Eqs. (4) and (5) are also explained in Figure 4 in which an example of the grid points is given. According to Eqs. (4) and $(5),\left(\Delta \mathrm{TEC}_{\mathrm{N}-\mathrm{S}}\right)$ is positive when northward and $\triangle \mathrm{TEC}_{\mathrm{E}-\mathrm{W}}$ is positive when eastward.

\subsection{Scintillation and TEC data mapping}

Ground Based Scintillation Climatology (GBSC) is a tool developed by INGV (Spogli et al. 2009; Alfonsi et al. 2011) aiming at highlighting climatological features of the 


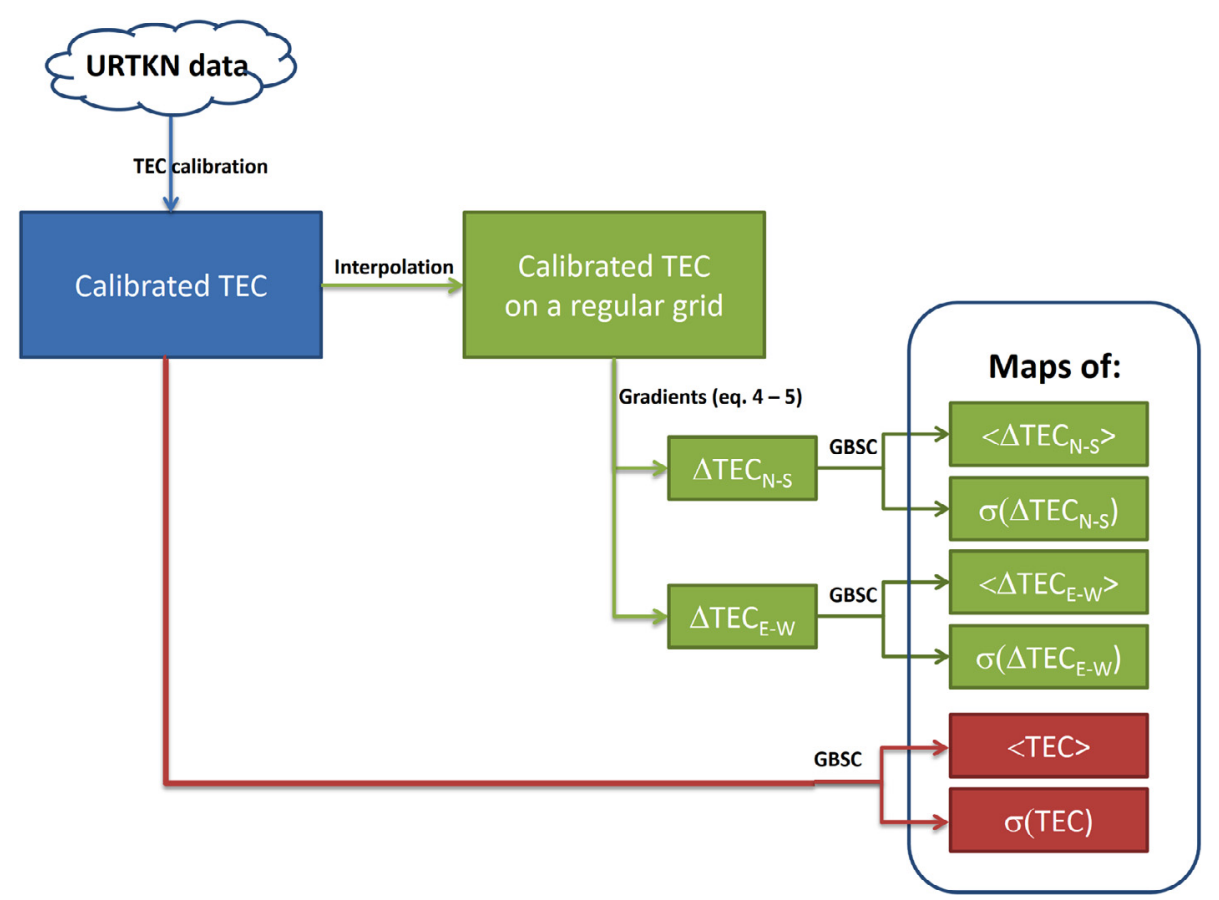

Fig. 6. Flowchart describing how GBSC maps of calibrated TEC and calibrated TEC gradients are obtained.

ionosphere. GBSC takes as input data acquired by GNSS ground-based receivers. By dividing the field of view of the receiver (or of a network) in bins, the technique is able to output different kinds of maps relative to the GNSS parameters considered. Typical outputs of the GBSC are:

- maps of mean and standard deviation of $S_{4}, \sigma_{\phi}$, TEC and Rate of TEC (ROT);

- maps of occurrence of same parameters above a userdefined threshold.

The occurrence is defined as follows:

$$
\mathrm{O}(\%)=\frac{N(p>T)}{N_{\text {tot }}}
$$

where $\mathrm{O}(\%)$ is the percentage occurrence, $N(p>T)$ is the number of measurements in which the parameter $p$ is greater than the threshold $T$ and $N_{\text {tot }}$ is the total number of measurements. Maps are expressed at $350 \mathrm{~km}$ above sea level, assuming the ionosphere as a single thin layer at the selected altitude.

The $S_{4}$ index, used in this study to characterize the scintillation occurrence, is projected to the vertical, as described in Rino (1979):

$$
S_{4}^{\text {vert }}=\frac{S_{4}^{\text {slant }}}{F\left(\alpha_{\text {elev }}\right)^{b}},
$$

where $S_{4}^{\text {slant }}$ is the amplitude scintillation index measured along the ray-path from the satellite to the receiver, i.e. the output of the receiver, $b$ is a coefficient depending on the spectral slope of detrended phase in the $0.1-25 \mathrm{~Hz}$ range (p) recorded by the receiver:

$$
b=\frac{p+1}{4} .
$$

$F\left(\alpha_{\text {elev }}\right)$ is the well-known obliquity factor mentioned in Mannucci et al. (1998), defined as:

$$
F\left(\alpha_{\text {elev }}\right)=\frac{1}{\sqrt{1-\left(\frac{R_{\mathrm{e}} \cos \alpha_{\mathrm{elev}}}{R_{\mathrm{e}}+H_{\mathrm{IPP}}}\right)^{2}}},
$$

in which $\alpha_{\text {elev }}$ is the elevation angle of the satellite, $R_{\mathrm{e}}$ is the radius of the Earth and $H_{\text {IPP }}$ is the height of the ionospheric pierce point, assumed as $350 \mathrm{~km}$.

The angular dependence of the scintillation index in Eq. (7) is valid under the conditions of weak scattering and when the single-phase screen approximation is applicable. However, we decided to apply the same formula also to characterize the moderate/strong scintillation, following the recommendations of Spogli et al. (2013), in which the verticalization procedure is justified by the climatological nature of the study and by the need of having a geometry-free mapping.

For this study, the technique is modified to assimilate data from the TEC interpolation and TEC gradients' computation described in the previous sections. Then, GBSC maps of mean and standard deviation of the calibrated TEC and TEC gradients are produced, according to the method described below.

The methods described in Section 2.2 to obtain TEC and TEC spatial gradients are combined with the GBSC mapping to obtain a climatological picture of TEC and TEC gradients' behaviour over São Paulo State, Brazil. A flowchart, describing how GBSC maps of calibrated TEC and calibrated TEC gradients are obtained starting from URTKN data, is given in Figure 6. Firstly, data from URTKN network are ingested by the TEC calibration algorithm (blue in the flowchart), in order to produce calibrated TEC values for each available satellite-receiver pair. Then, calibrated TEC is ingested by GBSC to produce maps of mean, $\langle$ TEC $\rangle$, and standard deviation, $\sigma$ (TEC) (red in the flowchart). In parallel, calibrated TEC data are interpolated on a regular grid and the N-S and E-W gradients are calculated (see Sect. 2.2). The maps of gradients 

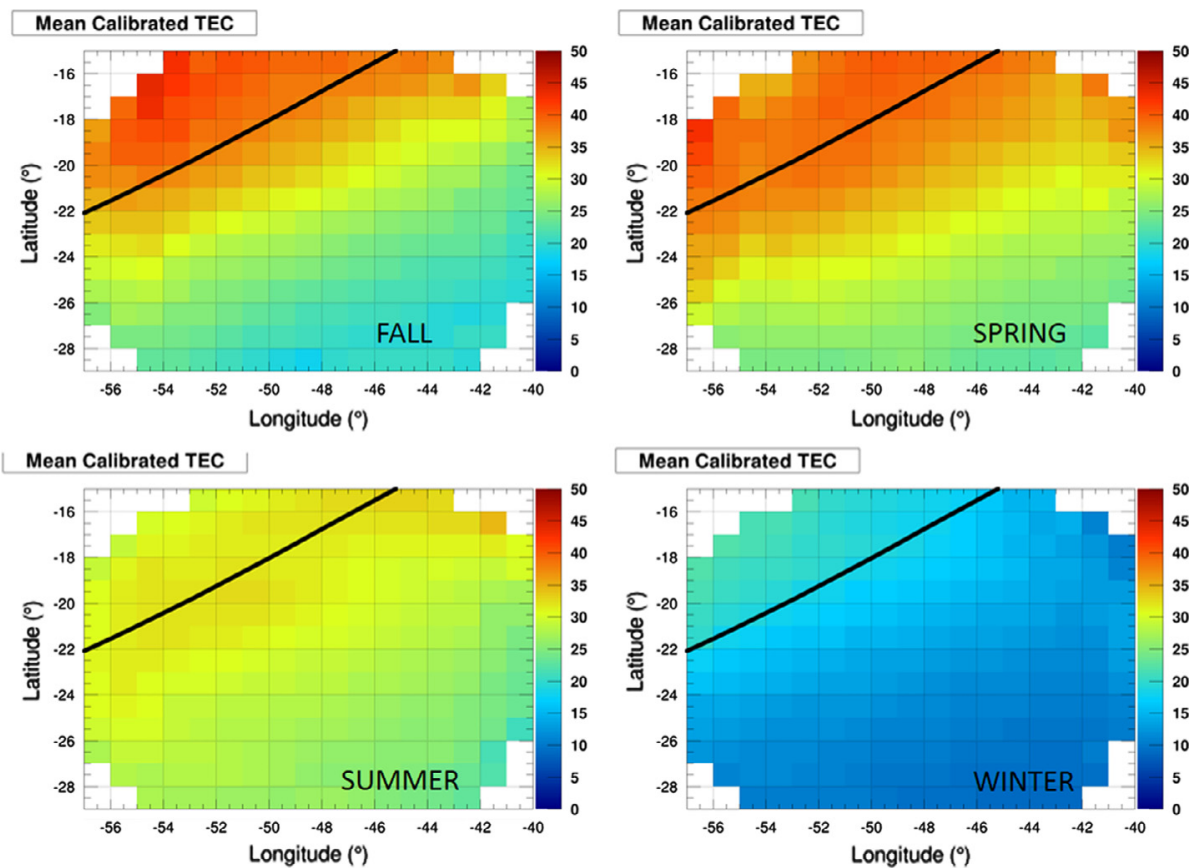

Fig. 7. GBSC maps of TEC (in TECU) during the whole 2012 for each season. Black line represents the 15th southern magnetic parallel.

are finally ingested by the modified GBSC to produce maps of mean, $\left\langle\Delta \mathrm{TEC}_{\mathrm{N}-\mathrm{S}}\right\rangle$ and $\left\langle\Delta \mathrm{TEC}_{\mathrm{E}-\mathrm{W}}\right\rangle$, and standard deviation, $\sigma\left(\Delta \mathrm{TEC}_{\mathrm{N}-\mathrm{S}}\right)$ and $\sigma\left(\Delta \mathrm{TEC} \mathrm{E}_{\mathrm{E}-\mathrm{W}}\right)$, of the gradients (green in the flowchart).

For the purpose of our study, calibrated TEC and calibrated TEC gradient maps are compared to the maps of occurrence of $S_{4}$ above 0.25 , assumed as the moderate/strong scintillation regime threshold. Such comparison allows highlighting the recurrent features of the ionospheric irregularities morphology in an attempt to identify eventual correspondences with scintillation occurrence.

\section{Results}

TEC, TEC gradients and the occurrence of moderate/strong amplitude scintillation are compared in order to investigate the ionosphere over the São Paulo state area. In particular, GBSC maps were constructed to cover an area between $-29^{\circ} \mathrm{N}$ and $-15^{\circ} \mathrm{N}$ in latitude and $-57^{\circ} \mathrm{E}$ and $-40^{\circ} \mathrm{E}$ in longitude.

Figure 7 shows the climatological distribution of $\langle$ TEC $\rangle$, sorted according to the seasons in 2012. It can be noted that, regardless of the season, the larger values of $\langle$ TEC $\rangle$ are located around $15^{\circ} \mathrm{S}$ magnetic latitude (black lines in Fig. 7). This is a signature of the enhancement of ionization, that identifies the southern crest of the EIA. Figure 7 also highlights the seasonal variation of the TEC distribution over the area of São Paulo, showing that during fall and spring $\langle\mathrm{TEC}\rangle$ reaches its maximum, increasing up to 50 TECU. During winter, a minimum of the $\langle\mathrm{TEC}\rangle$ can be noted, since it reaches only about 25 TECU. The position of the southern crest changes as well. In fact, during winter and fall the maximum of the ionization is located at lower magnetic latitude, i.e. toward the magnetic dip equator, with respect to the position held in summer and spring, when the crest moves southward. Hereafter, we refer to the equator and the pole as the dip equator and geomagnetic pole, respectively.

Figures 8-11 show the ionospheric conditions during summer, winter, spring and fall, respectively. According to the definitions given in Section 2.3, the six panels in each of such figures represent:

(a) the occurrence of $S_{4}>0.25$;

(b) the mean calibrated TEC gradients along N-S direction, $\left\langle\Delta \mathrm{TEC}_{\mathrm{N}-\mathrm{S}}\right\rangle$ (in TECU km${ }^{-1}$ );

(c) the mean calibrated TEC gradients along E-W direction, $\left\langle\Delta \mathrm{TEC}_{\mathrm{E}-\mathrm{W}}\right\rangle$ (in TECU km${ }^{-1}$ );

(d) the standard deviation of the calibrated TEC, $\sigma$ (TEC) (in TECU).

(e) the standard deviation of the calibrated TEC gradients along N-S direction, $\sigma\left(\Delta \mathrm{TEC}_{\mathrm{N}-\mathrm{S}}\right)$ (in TECU km${ }^{-1}$ );

(f) the standard deviation of the calibrated TEC gradients along E-W direction, $\sigma\left(\Delta \mathrm{TEC}_{\mathrm{E}-\mathrm{W}}\right)$ (in TECU km$\left.{ }^{-1}\right)$;

Analogously to Figure 7, the black line in each panel represents the 15th southern magnetic parallel, assumed as the average position of the southern crest of the EIA.

From the maps in panel a) of Figures 8-11, the occurrence of moderate/strong amplitude scintillation maximizes in spring and summer, reaching a peak occurrence of $20 \%$, while it is lower in fall and winter, when the occurrence is below 5\%. In each season, the enhancement of occurrence is mainly located on the equatorward edge of the southern crest of the EIA.

The maps of $\left\langle\Delta \mathrm{TEC}_{\mathrm{N}-\mathrm{S}}\right\rangle$ and $\left\langle\Delta \mathrm{TEC}_{\mathrm{E}-\mathrm{W}}\right\rangle$ (panels $\mathrm{b}$ and $\mathrm{c}$ of Figs. 8-11) show that $\mathrm{N}-\mathrm{S}$ gradients, reaching values up to $3 \times 10^{-5}$ TECU km$~^{-1}$ in spring and fall, are generally larger than their E-W counterparts. In fact, the maximum of $\left\langle\Delta \mathrm{TEC}_{\mathrm{E}-\mathrm{W}}\right\rangle$ is approximately $1 \times 10^{-5} \mathrm{TECU} \mathrm{km}^{-1}$ and, similarly to $\left\langle\Delta \mathrm{TEC}_{\mathrm{N}-\mathrm{S}}\right\rangle$, it is reached in spring and fall.

Both $\left\langle\Delta \mathrm{TEC}_{\mathrm{N}-\mathrm{S}}\right\rangle$ and $\left\langle\Delta \mathrm{TEC}_{\mathrm{E}-\mathrm{W}}\right\rangle$ change sign when crossing the EIA peak. From panel $b$ ), the N-S gradients are positive at magnetic latitudes greater than about $15^{\circ} \mathrm{S}$ (below the black line), i.e. poleward, and they become negative for magnetic latitudes smaller than $15^{\circ} \mathrm{S}$ (above the black line), i.e. equatorward. Zonal gradients show the same behaviour of the 


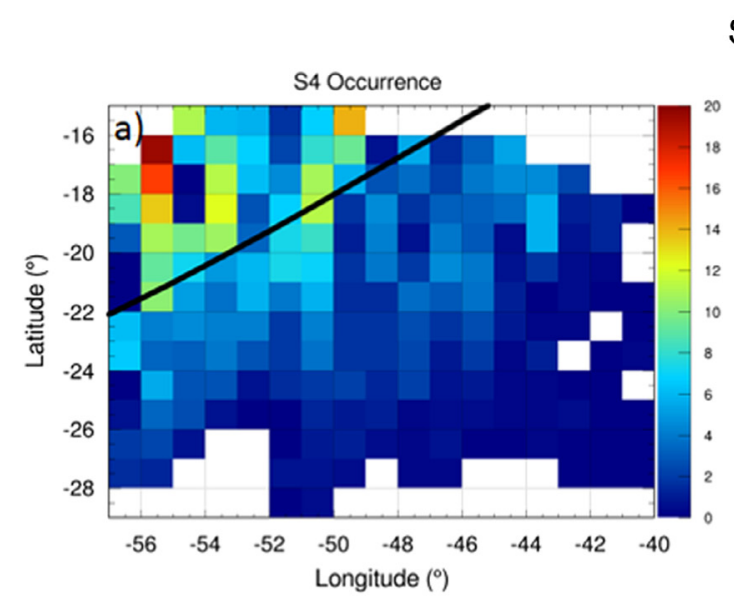

\section{SUMMER}
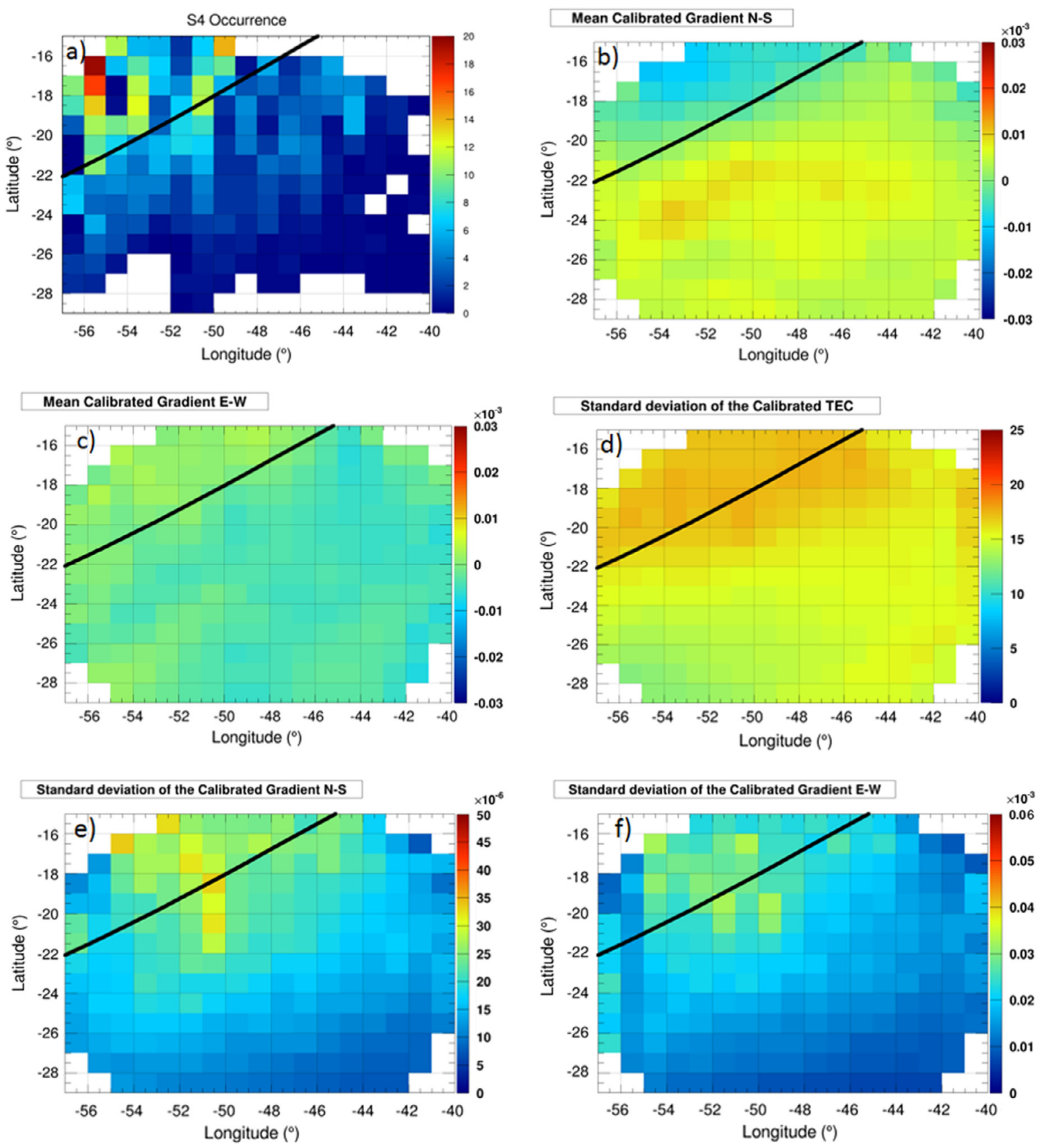

Fig. 8. Climatological maps of different ionospheric parameters from GBSC for summer days. $S_{4}$ occurrence (panel a), mean calibrated TEC gradients along N-S direction (in TECU km ${ }^{-1}$, panel b) and its standard deviation (in TECU km ${ }^{-1}$, panel e), mean calibrated TEC gradients along E-W direction (in TECU km ${ }^{-1}$, panel c) and its standard deviation (in TECU km ${ }^{-1}$, panel $\mathrm{f}$ ), standard deviation of the calibrated TEC (panel d, in TECU). Black lines represent 15th southern magnetic parallel.

meridional ones, as they change from negative to positive values when moving equatorward.

From the maps in panel d) of Figures 8-11, the standard deviation of the calibrated TEC, $\sigma$ (TEC), indicates that the variability of TEC maximizes during fall and spring, especially in spring when it reaches 25 TECU and minimizes in winter, being always below 15 TECU.

The maps of $\sigma\left(\Delta \mathrm{TEC}_{\mathrm{N}-\mathrm{S}}\right)$ and $\sigma\left(\Delta \mathrm{TEC}_{\mathrm{E}-\mathrm{W}}\right)$ (panels e and $\mathrm{f}$ of Figs. 8-11) represent the variability of the meridional and zonal gradients in each season. In agreement with what was found for $\left\langle\Delta \mathrm{TEC}_{\mathrm{N}-\mathrm{S}}\right\rangle$ and $\left\langle\Delta \mathrm{TEC}_{\mathrm{E}-\mathrm{W}}\right\rangle$ (panels $\mathrm{b}$ and $\mathrm{c}$ ), $\sigma\left(\Delta \mathrm{TEC}_{\mathrm{N}-\mathrm{S}}\right)$ is generally larger than $\sigma\left(\Delta \mathrm{TEC}_{\mathrm{E}-\mathrm{W}}\right)$ in each season. The enhancements of both $\sigma\left(\Delta \mathrm{TEC}_{\mathrm{N}-\mathrm{S}}\right)$ and $\sigma\left(\Delta \mathrm{TEC}_{\mathrm{E}-\mathrm{W}}\right)$ are in correspondence with the southern crest of the EIA, where the larger variability of fluctuations of TEC is expected to occur. It is interesting to note that during fall the distributions of $\sigma\left(\Delta \mathrm{TEC}_{\mathrm{N}-\mathrm{S}}\right)$ and $\sigma\left(\Delta \mathrm{TEC}_{\mathrm{E}-\mathrm{W}}\right)$ are smoother than in the other seasons.

The ionospheric sectors in which both zonal and meridional gradients $\left(\left\langle\Delta \mathrm{TEC}_{\mathrm{N}-\mathrm{S}}\right\rangle\right.$ and $\left\langle\Delta \mathrm{TEC}_{\mathrm{E}-\mathrm{W}}\right\rangle$ in panels $\mathrm{b}$ and $\left.\mathrm{c}\right)$ change in sign are in agreement with the maximum of the amplitude scintillation occurrence (panel a). In fact, the scintillation occurrence shows a maximum along the 15 th southern magnetic parallel, where gradients change direction. This highlights how spatial gradients of TEC and amplitude scintillation are strictly correlated in the region of the southern crest of the EIA. 


\section{WINTER}
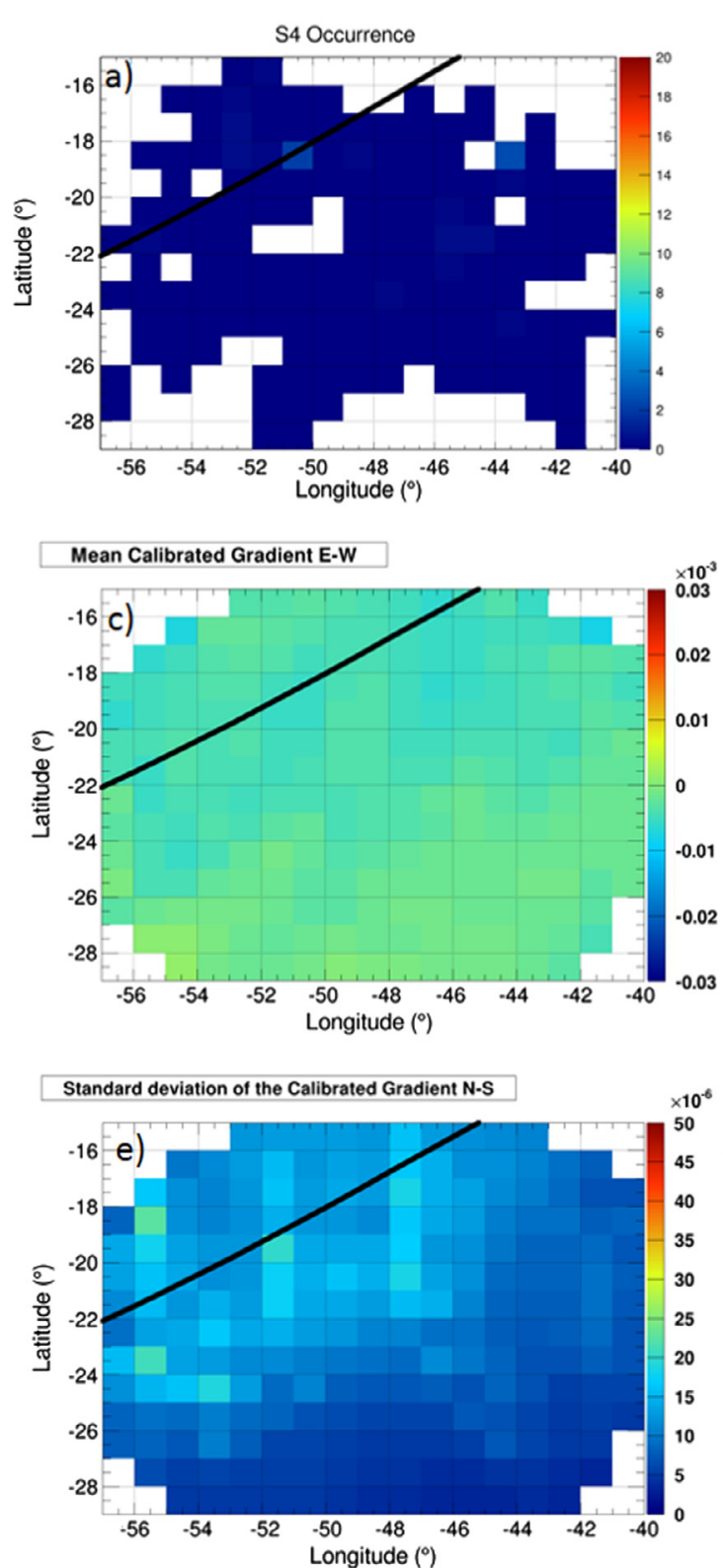
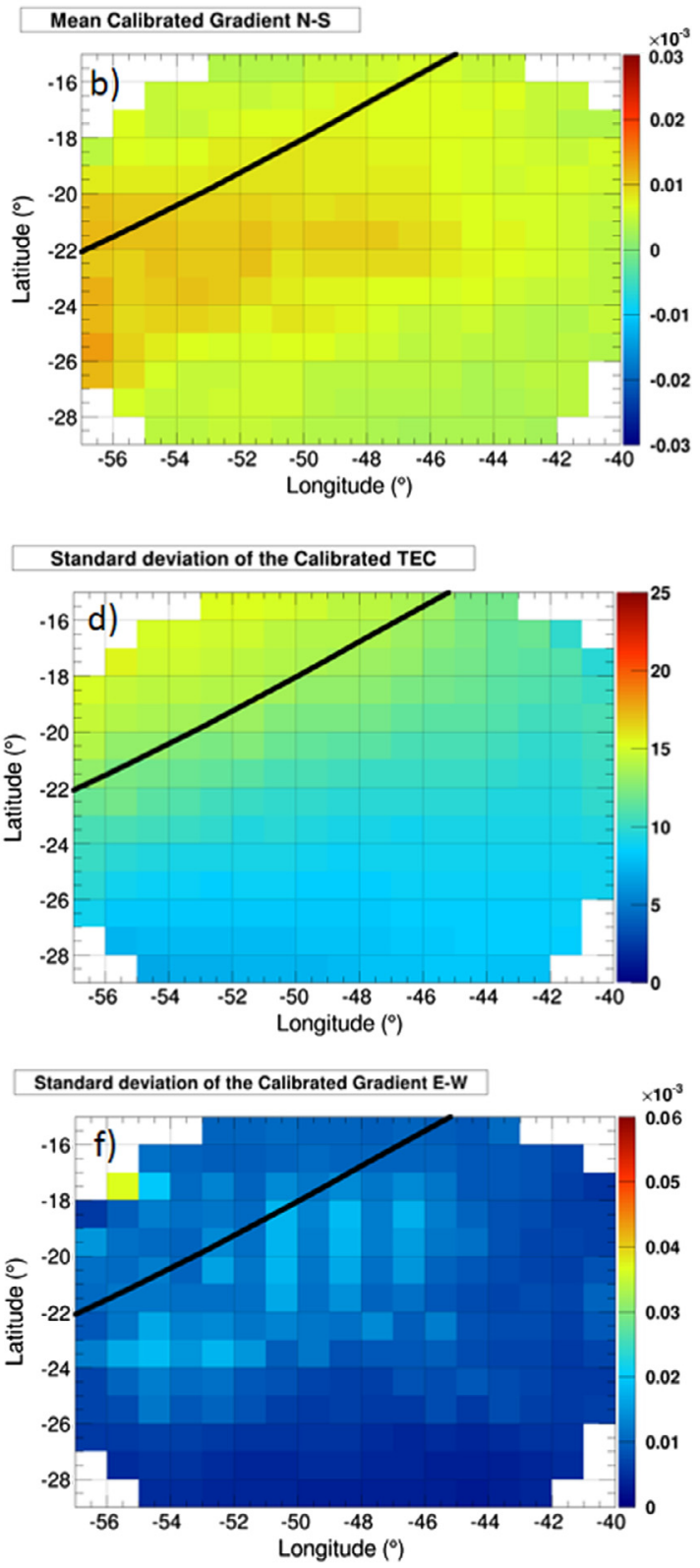

Fig. 9. Climatological maps of different ionospheric parameters from GBSC for winter days. $S_{4}$ occurrence (panel a), mean calibrated TEC gradients along N-S direction (in TECU km ${ }^{-1}$, panel b) and its standard deviation (in TECU km ${ }^{-1}$, panel e), mean calibrated TEC gradients along E-W direction (in TECU km ${ }^{-1}$, panel c) and its standard deviation (in TECU km ${ }^{-1}$, panel $\mathrm{f}$ ), standard deviation of the calibrated TEC (panel d, in TECU). Black lines represent 15th southern magnetic parallel.

Moreover, panels e) and f) show how larger values of $\sigma\left(\Delta \mathrm{TEC}_{\mathrm{N}-\mathrm{S}}\right)$ and $\sigma\left(\Delta \mathrm{TEC}_{\mathrm{E}-\mathrm{W}}\right)$ are in correspondence with the enhancement of the scintillation occurrence.

\section{Summary and discussion}

This study presents how, by disentangling the contribution to the TEC variations due to zonal and meridional gradients, it is possible to learn more about the relation between the scintillation occurrence and the morphology of the TEC variability. By integrating the TEC calibration into the GBSC technique, we discuss TEC variability in terms of two different quantities that give a statistical measure of how TEC changes in space:
- $\langle\Delta \mathrm{TEC}\rangle$

- $\sigma(\Delta \mathrm{TEC})$

expressed along the N-S and the E-W directions.

Inspired by the work of Alfonsi et al. (2011), in which the statistical meaning of the TEC variability is discussed in detail, here we stress that, if on one side $\langle\Delta \mathrm{TEC}\rangle$ gives indications on the magnitude of the gradients, on the other side $\sigma(\Delta T E C)$ indicates how large the intrinsic variability of the gradients is.

By comparing the zonal and the meridional components of $\langle\Delta \mathrm{TEC}\rangle$ and $\sigma(\Delta \mathrm{TEC})$, we found that the $\mathrm{N}-\mathrm{S}$ gradients are significantly larger than their E-W counterparts, regardless of the season. This reflects the fact that the ionospheric irregularities tend to elongate along the magnetic meridian, therefore 


\section{SPRING}
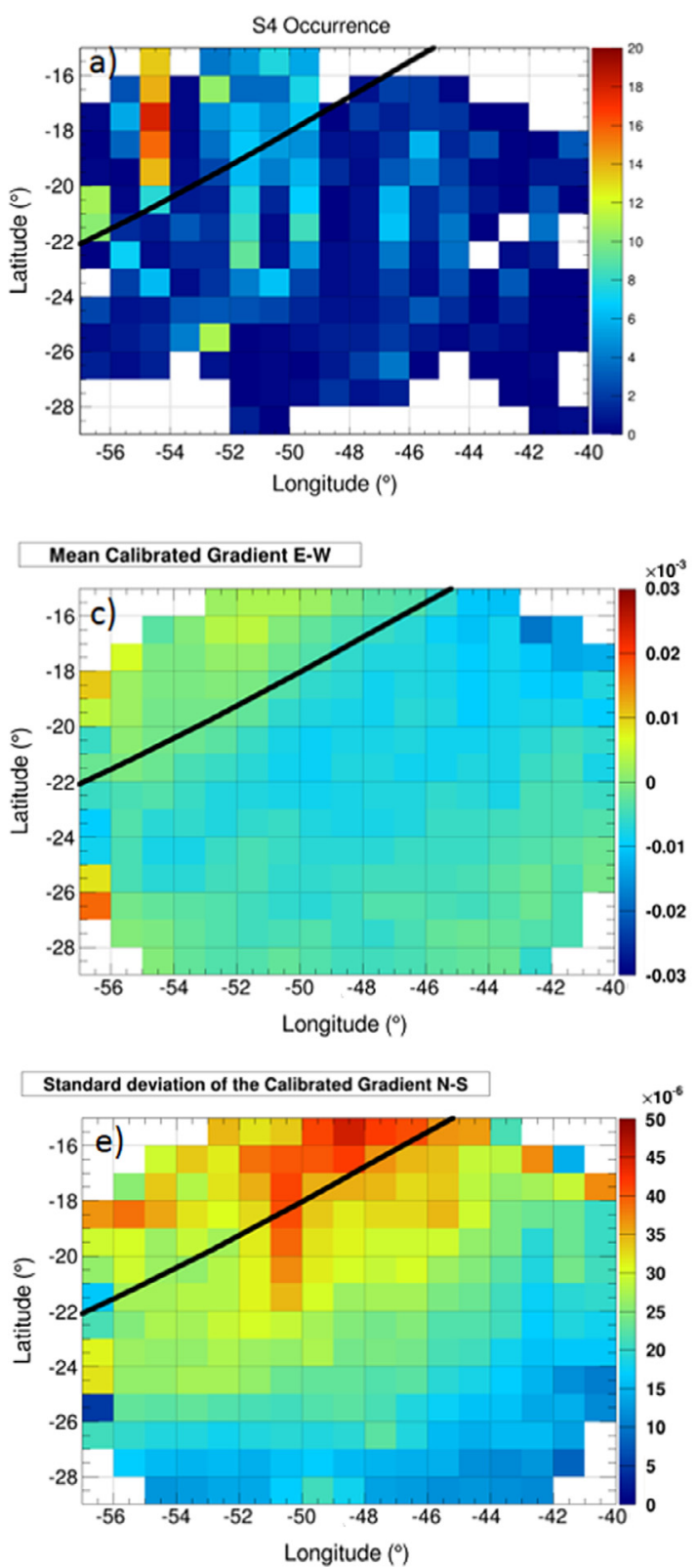
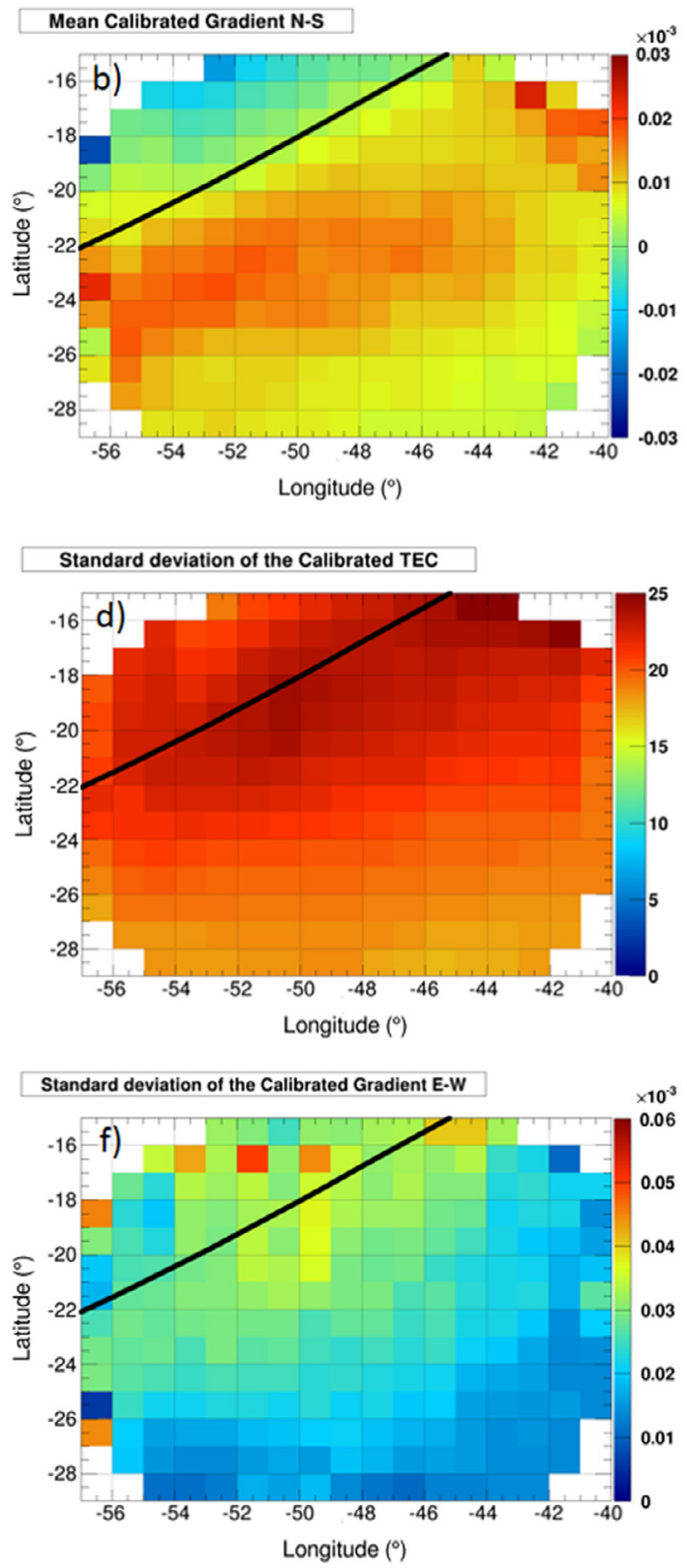

Fig. 10. Climatological maps of different ionospheric parameters from GBSC for spring days. $S_{4}$ occurrence (panel a), mean calibrated TEC gradients along N-S direction (in TECU km ${ }^{-1}$, panel b) and its standard deviation (in TECU km ${ }^{-1}$, panel e), mean calibrated TEC gradients along E-W direction (in TECU km ${ }^{-1}$, panel c) and its standard deviation (in TECU $\mathrm{km}^{-1}$, panel f), standard deviation of the calibrated TEC (panel d, in TECU). Black lines represent 15th southern magnetic parallel.

giving most of their contribution along the geographic N-S direction, as opposed to very little contribution on the E-W direction.

The most intriguing feature of our results stands in the observed relation among $\sigma\left(\Delta \mathrm{TEC}_{\mathrm{N}-\mathrm{S}}\right), \sigma\left(\Delta \mathrm{TEC}_{\mathrm{E}-\mathrm{W}}\right)$ and the scintillation occurrence. In particular, the correspondence with the $S_{4}$ occurrence indicates the variability of the N-S gradients as the principal driver of the amplitude scintillation. In detail: despite the fact that $\left\langle\Delta \mathrm{TEC}_{\mathrm{N}-\mathrm{S}}\right\rangle$ reaches larger values in fall than in spring, the level of scintillation is almost absent (below 6\%) in fall, while in spring it exacerbates. Thus, at least from a climatological standpoint, the presence of meaningful gradients alone is not sufficient to trigger the occurrence of scintillation. Instead, for this to happen, it must be associated with large variability of the gradients themselves. This is very noticeable and can drive future development of climatological models of scintillation for the low latitude ionosphere.

Moving forward from what is described in Muella et al. (2008), where the authors highlight, for some case events, that scintillations are likely to occur over the equatorward edge of the EIA southern crest, we confirmed the asymmetry of the scintillation occurrence over the two edges of the crest. In fact, as described in the previous section, by comparing the maps of scintillation occurrence and $\Delta \mathrm{TEC}_{\mathrm{N}-\mathrm{S}}$ it is possible to note an enhancement of the occurrence where the ionization decreases moving from the crest to the equator. 
FALL
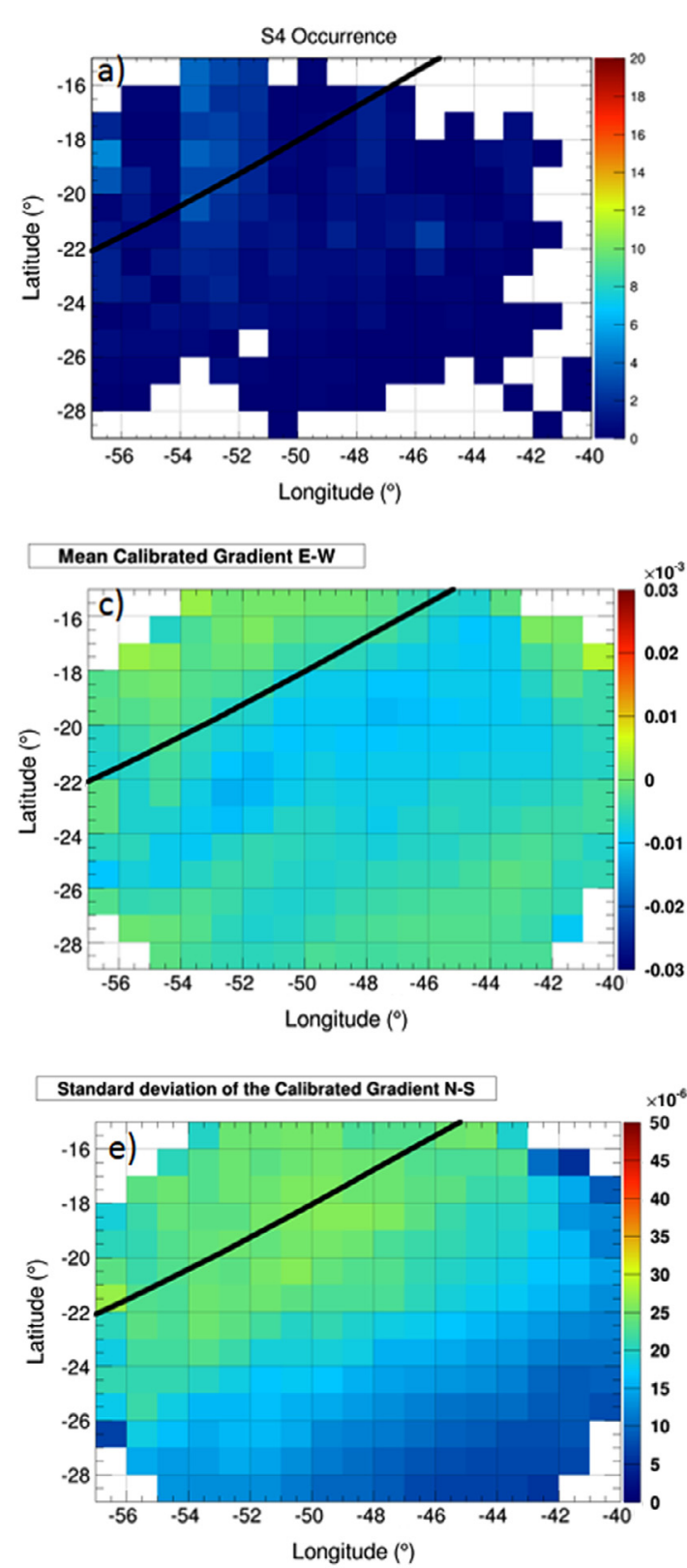
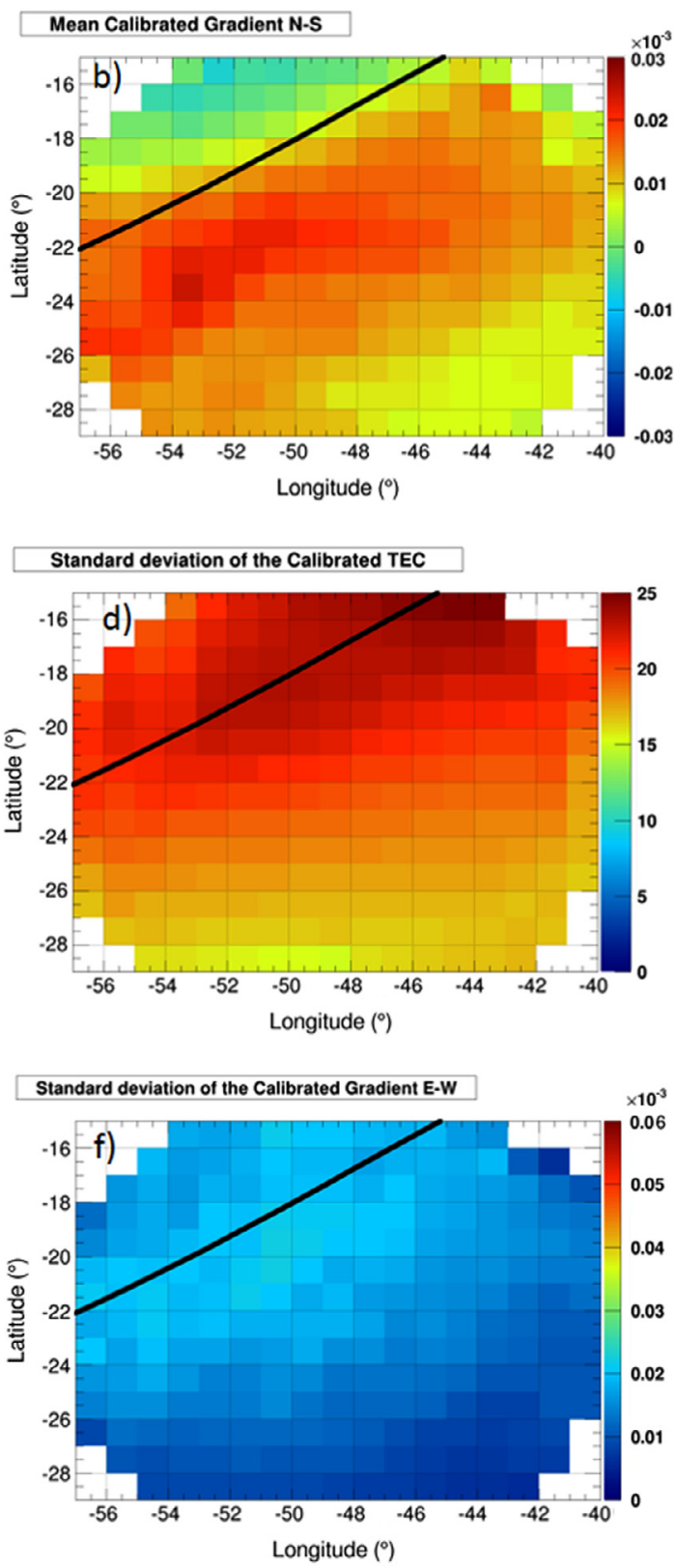

Fig. 11. Climatological maps of different ionospheric parameters from GBSC for fall days. $S_{4}$ occurrence (panel a), mean calibrated TEC gradients along N-S direction (in TECU km ${ }^{-1}$, panel b) and its standard deviation (in TECU km ${ }^{-1}$, panel e), mean calibrated TEC gradients along E-W direction (in TECU km ${ }^{-1}$, panel c) and its standard deviation (in TECU km ${ }^{-1}$, panel f), standard deviation of the calibrated TEC (panel d, in TECU). Black lines represent 15th southern magnetic parallel.

By investigating the seasonal variation of the EIA crest, with particular reference to its position in the Brazilian sector, it has been found that during winter and fall the maximum of the ionization is located at lower magnetic latitudes, i.e. toward the magnetic dip equator, with respect to the position in summer and spring, when the crest moves southward. This is in accordance with the pioneering work of Balan \& Iyer (1983) and references therein, in which the authors studied the latitudinal variation of the TEC in the EIA region in a few typical days of winter, summer and equinox by means of satellite radio beacon data. Also a recent study by Zhao et al. (2009) investigates the EIA behaviour, by using 9 years of GNSS-derived TEC measurements in the Asian-Australian sector. Even if they reach different results, likely due to the different longitudinal sectors investigated, the authors show the existence of a seasonal dependence in the position of the crests.

As expected, the TEC spatial gradients are also found to be larger during the equinoctial seasons than in the solstice seasons. The fall distributions of $\sigma\left(\Delta \mathrm{TEC}_{\mathrm{N}-\mathrm{S}}\right)$ and $\sigma\left(\Delta \mathrm{TEC}_{\mathrm{E}-\mathrm{W}}\right)$, smoother than the other seasons, are an open issue worth further investigating.

Acknowledgements. The authors thank IBGE for data from Rede Brasileira de Monitoramento Contínuo dos Sistemas GNSS and the CIGALA consortium for the scintillations data. C. Cesaroni thanks "PhD school in Geophysics" of University "Alma Mater Studiorum". The editor thanks Manuel Hernández-Pajares and Ashok Kumar Gwal for their assistance in evaluating this paper. 


\section{References}

Alfonsi, L., L. Spogli, G. De Franceschi, V. Romano, M. Aquino, A. Dodson, and C.N. Mitchell. Bipolar climatology of GPS ionospheric scintillation at solar minimum. Radio Sci., 46, RS0D05, 2011, DOI: 10.1029/2010RS004571.

Balan, N., and K.N. Iyer. Equatorial anomaly in ionospheric electron content and its relation to dynamo currents. J. Geophys. Res., 88, 10259, 1983, DOI: 10.1029/JA088iA12p10259.

Bevis, M., S. Businger, T.A. Herring, C. Rocken, R.A. Anthes, and R.H. Ware. GPS meteorology: remote sensing of atmospheric water vapor using the global positioning system. J. Geophys. Res., 97 (D14), 15787, 1992, DOI: 10.1029/92JD01517.

Blewitt, G., C. Kreemer, W.C. Hammond, H.P. Plag, S. Stein, and E. Okal. Rapid determination of earthquake magnitude using GPS for tsunami warning systems. Geophys. Res. Lett., 33 (11), L11309, 2006, DOI: 10.1029/2006GL026145.

Braasch, M.S. Global Positioning System: Theory and Applications. Chapter 14: Multipath Effects, vol. 1, American Institute of Aeronautics and Astronautics, Reston, VA, USA, 547-568, 1996, DOI: $10.2514 / 5.9781600866388 .0547 .0568$.

Ciraolo, L., F. Azpilicueta, C. Brunini, A. Meza, and S.M. Radicella. Calibration errors on experimental slant total electron content (TEC) determined with GPS. J. Geod., 81, 111-120, 2007, DOI: 10.1007/s00190-006-0093-1.

Finlay, C.C., S. Maus, C.D. Beggan, T.N. Bondar, A. Chambodut, et al. International geomagnetic reference field: the eleventh generation. Geophys. J. Int., 183 (3), 1216-1230, 2010, DOI: $10.1111 /$ j.1365-246X.2010.04804.x.

Foster, M.P., and A.N. Evans. An evaluation of interpolation techniques for reconstructing ionospheric TEC maps. IEEE Trans. Geosci. Remote Sens., 46 (7), 2153-2164, 2008,

DOI: $10.1109 /$ TGRS.2008.916642.

Frezzotti, M., A. Capra, and L. Vittuari. Comparison between glacier ice velocities inferred from GPS and sequential satellite images. Ann. Glaciol., 27, 54-60, 1998.

Kintner, P.M., B.M. Ledvina, and E.R. De Paula. GPS and ionospheric scintillations. Space Weather, 5 (9), S09003, 2007, DOI: $10.1029 / 2006$ SW000260.

Klobuchar, J.A., and M.A. Abdu. Equatorial ionospheric irregularities produced by the Brazilian Ionospheric Modification Experiment (BIME). J. Geophys. Res., 94, 2721, 1989, DOI: $10.1029 / J A 094 i A 03 p 02721$.

Koster, J.R. Equatorial scintillation. Planet. Space Sci., 20 (12), 1999-2014, 1972, DOI: 10.1016/0032-0633(72)90056-6.

Larson, K.M. GPS seismology, J. Geod., 83 (3-4), 227-233, 2009, DOI: $10.1007 / \mathrm{s} 00190-008-0233-\mathrm{x}$.

Lee, D.T., and B.J. Schachter, Two algorithms for constructing a Delaunay triangulation, Int. J. Comput. Inf. Sci., 9 (3), 219-242, 1980, DOI: 10.1007/BF00977785.

Mannucci, A.J., B.D. Wilson, D.N. Yuan, C.H. Ho, U.J. Lindqwister, and T.F. Runge. A global mapping technique for GPS-derived ionospheric total electron content measurements. Radio Sci., 33 (3), 565, 1998, DOI: 10.1029/97RS02707.
Muella, M.T.A.H., E.R. de Paula, I.J. Kantor, I.S. Batista, J.H.A. Sobral, M.A. Abdu, P.M. Kintner, K.M. Groves, and P.F. Smorigo. GPS L-band scintillations and ionospheric irregularity zonal drifts inferred at equatorial and low-latitude regions. J. Atmos. Sol. Terr. Phys., 70 (10), 1261-1272, 2008, DOI: $10.1016 /$ j.jastp.2008.03.013.

Muella, M.T.A.H., E.R. de Paula, and A.A. Monteiro. Ionospheric scintillation and dynamics of Fresnel-scale irregularities in the inner region of the equatorial ionization anomaly. Surv. Geophys., 34 (2), 233-251, 2013, DOI: 10.1007/s10712-012-9212-0.

Okabe, A., B. Boots, and K. Sugihara. Nearest neighbourhood operations with generalized Voronoi diagrams: a review. Int. J. Geogr. Inf. Syst., 8 (1), 43-71, 1994, DOI: $10.1080 / 02693799408901986$

Pi, X., A.J. Mannucci, U.J. Lindqwister, and C.M. Ho. Monitoring of global ionospheric irregularities using the worldwide GPS network. Geophys. Res. Lett., 24, 2283, 1997, DOI: 10.1029/97GL02273.

Rino, C.L. A power law phase screen model for ionospheric scintillation: 2. Strong scatter. Radio Sci., 14, 1147, 1979 , DOI: $10.1029 / \mathrm{RS} 014 \mathrm{i006p01147.}$

Sekido, M., T. Kondo, E. Kawai, and M. Imae. Evaluation of GPSbased ionospheric TEC map by comparing with VLBI data. Radio Sci, 38 (4), n/a-n/a, 2003, DOI: 10.1029/2000RS002620.

Shimada, S., Y. Fujinawa, S. Sekiguchi, and S. Ohmi. Detection of a volcanic fracture opening in Japan using Global Positioning System measurements. Nature, 343, 631-633, 1990, DOI: $10.1038 / 343631 \mathrm{a} 0$.

Spogli, L., L. Alfonsi, G. De Franceschi, V. Romano, M.H.O. Aquino, and A. Dodson. Climatology of GPS ionospheric scintillations over high and mid-latitude European regions. Ann. Geophys., 27 (9), 3429-3437, 2009 , DOI: 10.5194/angeo-27-3429-2009.

Spogli, L., L. Alfonsi, V. Romano, G. De Franceschi, G.M. Joao Francisco, M. Hirokazu Shimabukuro, B. Bougard, and M. Aquino. Assessing the GNSS scintillation climate over Brazil under increasing solar activity. J. Atmos. Sol. Terr. Phys., 105-106, 199-206, 2013, DOI: 10.1016/j.jastp.2013.10.003.

Sreeja, V., M. Aquino, Z.G. Elmas, and B. Forte. Correlation analysis between ionospheric scintillation levels and receiver tracking performance. Space Weather, 10 (6), S06005, 2012, DOI: $10.1029 / 2012$ SW000769.

Wernik, A.W., and C.H. Liu. Ionospheric irregularities causing scintillation of $\mathrm{GHz}$ frequency radio signals. J. Atmos. Terr. Phys., 36 (5), 871-879, 1974, DOI: $10.1016 / 0021-9169(74) 90032-4$

Yeh, K.C., and G.W. Swenson. The scintillation of radio signals from satellites. J. Geophys. Res., 64 (12), 2281-2286, 1959, DOI: $10.1029 / \mathrm{JZ} 064 \mathrm{i} 012 \mathrm{p} 02281$.

Zhao, B., W. Wan, L. Liu, and Z. Ren. Characteristics of the ionospheric total electron content of the equatorial ionization anomaly in the Asian-Australian region during 1996-2004. Ann. Geophys., 27 (10), 3861-3873, 2009, DOI: 10.5194/angeo-27-3861-2009.

Cite this article as: Cesaroni C, Spogli L, Alfonsi L, De Franceschi G, Ciraolo L, et al. L-band scintillations and calibrated total electron content gradients over Brazil during the last solar maximum. J. Space Weather Space Clim., 5, A36, 2015, DOI: 10.1051/swsc/2015038. 